\title{
Regional cerebral blood flow (rCBF) and cerebral vasoreactivity in patients with retinal ischaemic symptoms
}

\author{
EMILIA KERTY,* DAVID RUSSELL,* SØREN J BAKKE, \\ ROLF NYBERG-HANSEN,* KJELL ROOTWELL \\ From the Departments of Neurology, ${ }^{*}$ Radiology, Section of Neuroradiology $\dagger$ and Institute of Clinical \\ Biochemistry, $\ddagger$ Rikshospitalet, The National Hospital, University of Oslo, Norway
}

SUMMARY Regional cerebral blood flow (rCBF) and cerebral vasoreactivity were assessed in 28 consecutive patients who presented with retinal ischaemic symptoms, without clinical or cerebral CT evidence of cerebral ischaemia. rCBF was measured using xenon-133 inhalation and single photon emission computed tomography before and 20 minutes after the intravenous administration of $1 \mathrm{~g}$ acetazolamide. The findings suggest that patients with retinal ischaemic symptoms alone due to carotid atherosclerosis often have a carotid lesion which is of haemodynamic significance with regard to cerebral perfusion and vasoreactivity. Furthermore, localized areas with reduced cerebral perfusion may also be present in some patients, without evidence of precerebral carotid occlusive disease.

Retinal ischaemic symptoms often suggest the presence of an embolic source in the ipsilateral carotid artery. ${ }^{1-3}$ Although these symptoms may present without clinical evidence of cerebrovascular disease they predict an increased risk for cerebral TIAs and ischaemic stroke. ${ }^{4-5}$ The status of cerebral perfusion and intracranial haemodynamics in these patients is therefore of interest.

The purpose of this study was to assess regional cerebral blood flow (rCBF) and cerebral vasoreactivity in patients with retinal ischaemic symptoms who did not have a history of cerebral transient ischaemic attacks (TIA) or stroke, or cerebral CT evidence of cerebral ischemia.

\section{Patients and methods}

Twenty-eight consecutive patients who presented with amaurosis fugax or acute monocular visual field defects took part in the study. There were 17 males and 11 females, aged 23-78 years (mean 55). Patients were excluded if they had a history of cerebral TIAs or stroke, or evidence of infarction on cerebral CT examination. None of the patients suffered from migraine and they were not regularly taking medication of any kind.

Correspondence to: Emilia Kerty MD, Department of Neurology, Rikshospitalet, The National Hospital, 0027 Oslo 1, Norway.

Received 21 March 1989.

Accepted 14 July 1989
All patients underwent a detailed neurological, neuroophthalmological and cardiological examination including ECG. Echocardiography was carried out in 24 patients and coagulation stätus was assessed in 22. Pulsed Doppler spectral analysis (SD 100 Vingmed Inc, Oslo, Norway) was carried out on the precerebral carotid arteries of all 28 patients. Details regarding this examination and the assessment of results have been reported previously. ${ }^{6}$ Angiography was carried out in 15 of the patients; conventional arteriography in 11 patients, intravenous digital subtraction angiography in two and intra-arterial digital subtraction angiography in two patients.

\section{rCBF measurements}

rCBF was measured using xenon-133 inhalation and single photon emission computed tomography (Tomomatic 64, Medimatic Inc, Copenhagen, Denmark). This method has been described in detail elsewhere. ${ }^{7}$ Using high sensitivity collimators three slices of the brain are studied simultaneously. The slices are $2 \mathrm{~cm}$ thick and routinely positioned 2,6 and $10 \mathrm{~cm}$ above the orbitomeatal plane (OM). The resolution in the plane of each slide is $1.7 \mathrm{~cm}$ (full width, half maximum). The interval between the last retinal ischaemic episode and the rCBF measurements was from 1-90 days, mean $51 \mathrm{SD} 1 \cdot 3$ days.

rCBF values were calculated in standardised regions of interest in slice $2(\mathrm{OM}+6 \mathrm{~cm})$ corresponding approximately to the perfusion territory of the anterior cerebral (ACA), the anterior (aMCA) and posterior branches (pMCA) of the middle (MCA) and of the posterior cerebral artery (PCA). ${ }^{7}$ This was obtained by using a software package for automatic calculation of flow values in regions of interest.

Each rCBF study consisted of two measurements. Follow- 
ing a baseline examination, $1 \mathrm{~g}$ acetazolamide was given intravenously, and the rCBF measurements were repeated approximately 20 minutes later. End-expiratory $\mathrm{pCO}_{2}$ was measured by an infra-red capnograph (Datex CD 102 Normocap, Datex Instrumentation Corp, Helsinki, Finland). Correction of $\mathrm{rCBF}$ values for $\mathrm{PCO}_{2}$ was not carried out.

rCBF values in patients were compared to those in 25 healthy control subjects, 12 of whom had been given acetazolamide. $^{7}$

\section{Statistical methods}

The results are presented as mean, SEM (standard error of the mean) or mean with a $95 \%$ confidence interval. The Student procedure was used for calculating the confidence intervals. ${ }^{8}$ One-tailed statistical tests were found to be the most appropriate. Differences or changes were considered statistically significant if the $p$ value was less or equal to a level of $5 \%$. For differences in the same patient the Student test for paired comparison was used. The two sample Student test was used for comparison between groups.

In individual patients reduced baseline $\mathrm{rCBF}$ or a reduced response to acetazolamide was considered to be present if side-to-side asymmetry in a region of interest exceeded the $95 \%$ fractile for the controls.

\section{Results}

\section{Clinical findings}

Eighteen (64\%) patients had experienced amaurosis fugax and $10(36 \%)$ had suffered permanent visual disturbances. Fourteen patients had symptoms on the left side and 14 on the right. The amaurosis fugax attacks had lasted for a few minutes in the majority of patients, and in all less than one hour. In all 18 patients with amaurosis fugax the neuro-ophthalmological examination was normal.

Neuro-ophthalmological examination in the 10 patients with permanent visual disturbances showed that three had an occlusion of the central retinal artery on the symptomatic side with reduced visual acuity. The remaining seven patients had branch occlusion of this artery with normal or only slightly reduced visual acuity and permanent sector-shaped visual field defects. Neurological examination was otherwise normal in all patients.

The cardiological assessment including echocardiography $(n=24)$ was normal in all patients, and assessment of coagulation status, carried out in 22 patients, was normal in 20 . One patient had protein-S insufficiency and another decreased factor VII with a slightly increased bleeding time.

\section{Doppler and angiographic findings}

The Doppler and angiographic examinations detected an atherosclerotic lesion in the precerebral internal carotid artery (ICA) ipsilateral to symptoms in 11 $(39 \%)$ of the 28 patients (Patient group A). These lesions reduced the diameter of the ICA by $<50 \%$ in two, $>75 \%$ in six and in three patients the ICA was occluded. In the ICA contralateral to symptoms, four patients had an atherosclerotic lesion which reduced the diameter of the vessel by $<25 \%$. Findings in the vertebral arteries were normal.

In $17(61 \%)$ patients the Doppler $(n=17)$ and angiographic $(n=4)$ examinations showed normal findings in the carotid and vertebral arteries on both the symptomatic and the contralateral side. (Patient group B)

\section{Correlation of clinical and Doppler/angiographic findings}

The 11 patients with carotid occlusive disease ipsilateral to symptoms (Group A), consisted of seven men and four women, aged 44-77 years, mean 63, SEM 2.7 years. Seven of these patients had experienced amaurosis fugax, one had central retinal artery occlusion and three had branch occlusion of this artery.

The remaining 17 patients who did not have evidence of carotid occlusive disease (Group B), were ten men and seven women, aged $23-73$ years, mean 50 , SEM 3.7 years. Eleven of these patients had experienced amaurosis fugax, two central retinal arteryo occlusion and four branch occlusion of this artery.

\section{$r C B F$ findings}

Group A: Patients with carotid occlusive disease $(n=11)$. Mean baseline $\mathrm{rCBF}$ values in the $1 \frac{1}{2}$ patients with carotid occlusive disease ipsilateral to symptoms were significantly $(p<0.01)$ lower in af regions of interest on the symptomatic compared with the contralateral side (table 1, fig 1). Values in all regions of interest were also significantly lower on both the symptomatic $(\mathrm{p}<0.005)$ and the contralateral $(\mathrm{p}<0.05)$ side when compared with those in the control group ( $95 \%$ confidence interval). Mean $\mathrm{pCO}_{2}$ values in these patients and the controls were not significantly different (table 1).

The mean response to acetazolamide in these patients was significantly $(p<0.01)$ reduced in all regions of interest on the symptomatic compared with the contralateral side (table 1, fig 1). When compared with control values $(95 \%$ confidence interval) the acetazolamide response was significantly $(p<0.05)$ reduced in all regions of interest on the symptomatic side and in the ACA perfusion territory on the contralateral side (table 1, fig 1). The side-to-side asymmetry of the acetazolamide response was also significantly $(p<0.05)$ greater in the ACA and aMCA perfusion territories compared with the controls (table 2, fig 2). This was not the case for the pMCA and PCA territories. There was no significant difference with regard to the decrease in $\mathrm{pCO}_{2}$ after acetazolamide administration in these patients and the

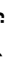


Table 1 Baseline $r C B F$ values and the acetazolamide response (mean, SEM) in the perfusion territory of the anterior cerebral ( $A C A)$, the anterior ( $A M C A)$ and posterior ( $p M C A)$ branches of the middle cerebral, and the posterior cerebral artery $(P C A)$ in 11 patients with retinal ischaemic symptoms alone who had ipsilateral precerebral carotid occlusive disease (Group $A$ )

\begin{tabular}{|c|c|c|c|c|c|c|}
\hline \multirow[b]{3}{*}{$\begin{array}{l}\text { Perfusion } \\
\text { territory }\end{array}$} & \multicolumn{6}{|c|}{$r C B F$ values $(\mathrm{ml} / 100 \mathrm{~g} / \mathrm{min})$} \\
\hline & \multicolumn{3}{|c|}{ Baseline values } & \multicolumn{3}{|c|}{ Acetazolamide response } \\
\hline & $\begin{array}{l}\text { Symptom } \\
\text { side }\end{array}$ & $\begin{array}{l}\text { Contralat } \\
\text { side }\end{array}$ & $\begin{array}{l}\text { Control values } \\
(n=25)\end{array}$ & $\begin{array}{l}\text { Symptom } \\
\text { side }\end{array}$ & $\begin{array}{l}\text { Contralat } \\
\text { side }\end{array}$ & $\begin{array}{l}\text { Control values } \\
(n=12)\end{array}$ \\
\hline $\begin{array}{l}\text { ACA } \\
\text { aMCA } \\
\text { pMCA } \\
\text { PCA } \\
\text { pCO }(m m H g)\end{array}$ & $\begin{array}{l}48 \cdot 7,2 \cdot 4 \\
55 \cdot 1,2 \cdot 7 \\
50 \cdot 8,2 \cdot 5 \\
48 \cdot 6,2 \cdot 2 \\
3\end{array}$ & $\begin{array}{l}51 \cdot 0,2 \cdot 5 \\
58 \cdot 0,3 \cdot 3 \\
53 \cdot 3,2 \cdot 6 \\
51 \cdot 4,2 \cdot 2\end{array}$ & $\begin{array}{l}56 \cdot 0,1 \cdot 3 \\
65 \cdot 9,1 \cdot 5 \\
58 \cdot 1,1 \cdot 3 \\
54 \cdot 5,1 \cdot 1 \\
40 \cdot 9,1 \cdot 1\end{array}$ & $\begin{array}{r}7 \cdot 4,2 \cdot 2 \\
8 \cdot 7,2 \cdot 1 \\
9 \cdot 0,1 \cdot 6 \\
10 \cdot 9,1 \cdot 9 \\
3\end{array}$ & $\begin{array}{r}9 \cdot 5,2 \cdot 0 \\
13 \cdot 5,2 \cdot 2 \\
12 \cdot 6,2 \cdot 1 \\
11 \cdot 7,2 \cdot 4\end{array}$ & $\begin{array}{l}13 \cdot 5,1 \cdot 2 \\
15 \cdot 6,1 \cdot 6 \\
15 \cdot 0,1 \cdot 4 \\
15 \cdot 0,2 \cdot 1 \\
37 \cdot 8,1 \cdot 0\end{array}$ \\
\hline
\end{tabular}

controls (patients: $3 \cdot 7$, SEM $1 \cdot 2 \mathrm{mmHg}$, controls $3 \cdot 1$, SEM $1 \cdot 2 \mathrm{mmHg}$ ).

Assessment of the results in each of the patients in this group showed the following in the MCA and/or ACA territories ipsilateral to their symptoms and carotid occlusive disease: three patients had normal baseline $\mathrm{rCBF}$ and a reduced acetazolamide response; two reduced baseline rCBF and a normal acetazolamide response and in three both baseline values and the acetazolamide response were reduced. Group B: Patients without carotid occlusive disease $(n=17)$. Mean baseline $\mathrm{rCBF}$ values for the 17 patients without evidence of carotid occlusive disease did not differ significantly on the symptomatic compared with the contralateral side (table 3). However, flow values were significantly $(p<0.05)$ lower in all regions of interest on both sides when compared with

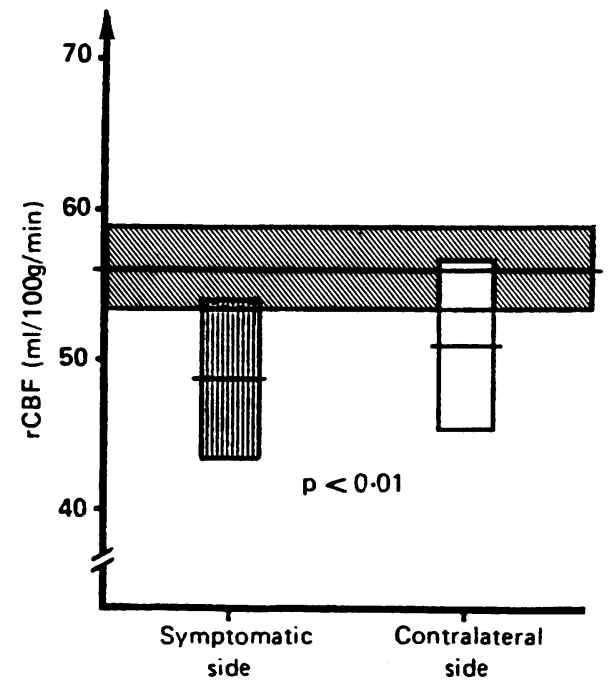

the $95 \%$ confidence interval for the control group. Mean $\mathrm{pCO}_{2}$ values and the decrease in $\mathrm{pCO}_{2}$ after acetazolamide administration (patients: $2 \cdot 8$, SEM $1.2 \mathrm{mmHg}$, controls: $3 \cdot 1$, SEM $1.2 \mathrm{mmHg}$ ) were not significantly different in these patients and the controls (table 3). The response to acetazolamide was normal in all regions of interest in these patients. The side-to-side asymmetry of the acetazolamide response did not differ from the controls in any region of interest (table 2).

Four $(24 \%)$ of the 17 patients in this group had regions of interest with reduced baseline $\mathrm{rCBF}$ on the symptomatic compared with the contralateral side. In two patients this reduction was in the ACA perfusion territory, in one both the ACA and aMCA and in one patient in the aMCA and pMCA perfusion territories. The response to acetazolamide was normal in all

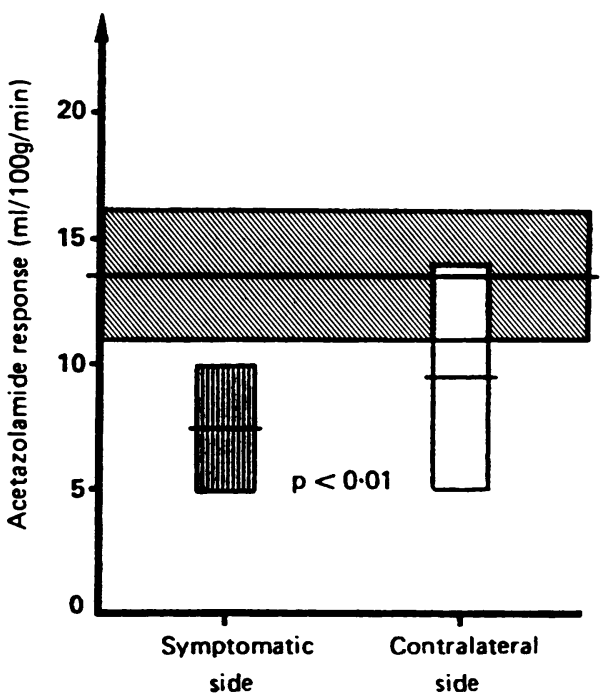

Fig 1 Baseline $C B$ BF values (left) and the acetazolamide response (right) in the anterior cerebral artery perfusion territory ( ACA) of 11 patients with ipsilateral carotid occlusive disease who had retinal ischaemic symptoms alone. Flow values are given as mean with a $95 \%$ confidence interval of the patients two sides. The grey area shows mean and $95 \%$ confidence interval for controls. $p$ values compare the symptomatic and the contralateral side. 


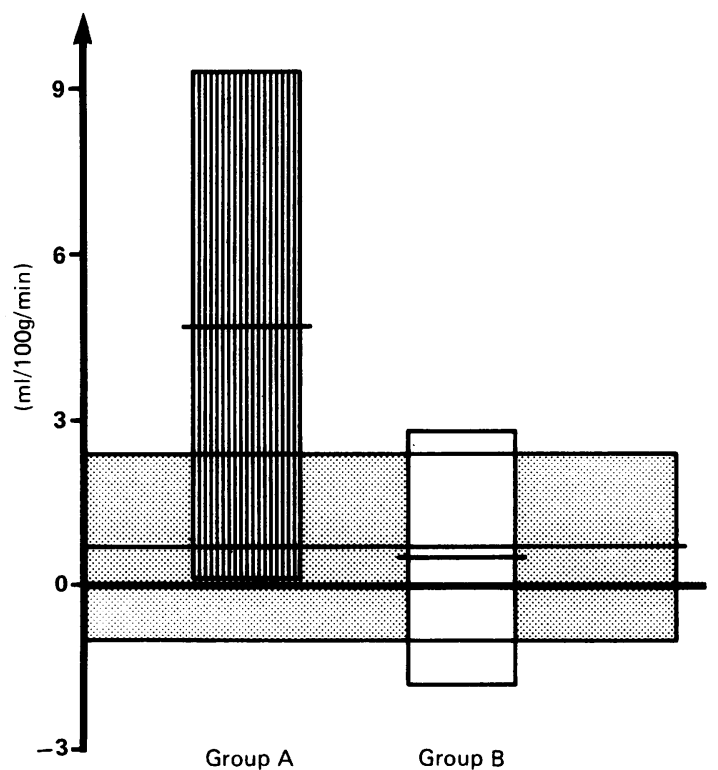

Fig 2 Side-to-side asymmetry of the acetazolamide response in the perfusion territory of the anterior branches of the middle cerebral artery (aMCA) in 11 patients with (Group $A$ ) and in 17 patients without (Group B) carotid occlusive disease. Flow values are given as mean with a $95 \%$ confidence interval. The grey area shows mean and $95 \%$ confidence interval for controls.

regions of interest in these patients. Cerebral magnetic resonance imaging (MRI) was carried out in these four patients, and in one showed small high intensity areas on $T_{2}$ weighted images consistent with ischaemic lesions which had the same location as the reduced rCBF. This patient was a 56 year old woman who presented with left-sided branch occlusion of the central retinal artery. In the remaining three patients the MRI findings were normal.
Table 2 Side-to-side asymmetry of the acetazolamide response (mean, SEM) in group $A$ and B patients. Perfusion territories as in table 1. Statistical comparison with control values.

\begin{tabular}{|c|c|c|c|}
\hline \multirow[b]{3}{*}{$\begin{array}{l}\text { Perfusion } \\
\text { territory }\end{array}$} & \multicolumn{3}{|c|}{$r C B F$ values $(\mathrm{ml} / 100 \mathrm{~g} / \mathrm{min})$} \\
\hline & \multicolumn{3}{|c|}{ Asymmetry of the acetazolamide response } \\
\hline & $\begin{array}{l}\text { Group } A \\
(n=I I)\end{array}$ & $\begin{array}{l}\text { Group B } \\
(n=17)\end{array}$ & $\begin{array}{l}\text { Controls } \\
(n=12)\end{array}$ \\
\hline $\begin{array}{l}\text { ACA } \\
\text { aMCA } \\
\text { pMCA } \\
\text { PCA }\end{array}$ & $\begin{array}{l}2 \cdot 2,1 \cdot 0^{* *} \\
4 \cdot 7,2 \cdot 1^{* *} \\
3 \cdot 6,2 \cdot 1^{*} \\
0 \cdot 8,1 \cdot 1^{*}\end{array}$ & $\begin{array}{r}0 \cdot 2,0 \cdot 8^{*} \\
0 \cdot 5,1 \cdot 1^{*} \\
1 \cdot 5,1 \cdot 0^{*} \\
-0 \cdot 4,1 \cdot 0^{*}\end{array}$ & $\begin{array}{r}0.3,0.7 \\
0.7,0.8 \\
1 \cdot 1,0.6 \\
-0.6,0.7\end{array}$ \\
\hline
\end{tabular}

*not significant, ${ }^{* *} \mathrm{p}<0.005$.

\section{Discussion}

All of the 28 patients in this study presented with $\overrightarrow{\vec{\omega}}$ retinal ischaemic symptoms alone, and did not have clinical or cerebral CT evidence of cerebral ischaemia or infarction. Angiography and Doppler examinations revealed, however, that $11(39 \%)$ had an athero- ? sclerotic lesion in the precerebral ICA ipsilateral to $\vec{N}$ their visual symptoms (Group A). In these patient $\vec{\omega}$ mean baseline rCBF values and the response to acetazolamide were significantly lower in the hemis phere ipsilateral to symptoms compared with th contralateral side. The side-to-side asymmetry of the response was significantly greater than in controls Baseline rCBF values in all regions of interee contralateral to symptoms and the response to. acetazolamide in the ACA perfusion territory on th side were also significantly lower than control values.

In the 17 patients with no evidence of precerebral carotid occlusive disease (Group B), baseline rCBF values in all regions of interest on both the symptomatic and the contralateral side were significantly lower than those in the control group. However, values for the two sides did not differ significantly, and the acetazolamide response in all regions of interest as

Table 3 Baseline $C B F$ values and the acetazolamide response (mean, SEM) in the same perfusion territories as in table 1, in 17 patients with retinal ischaemic symptoms alone who had normal precerebral carotid arteries (Group B). Perfusion territories as in table 1.

\begin{tabular}{|c|c|c|c|c|c|c|}
\hline \multirow[b]{3}{*}{$\begin{array}{l}\text { Perfusion } \\
\text { territory }\end{array}$} & \multicolumn{6}{|c|}{$r C B F$ values $(\mathrm{ml} / 100 \mathrm{~g} / \mathrm{min})$} \\
\hline & \multicolumn{3}{|c|}{ Baseline values } & \multicolumn{3}{|c|}{ Acetazolamide response } \\
\hline & $\begin{array}{l}\text { Symptom } \\
\text { side }\end{array}$ & $\begin{array}{l}\text { Contralat } \\
\text { side }\end{array}$ & $\begin{array}{l}\text { Control values } \\
(n=25)\end{array}$ & $\begin{array}{l}\text { Symptom } \\
\text { side }\end{array}$ & $\begin{array}{l}\text { Contralat } \\
\text { side }\end{array}$ & $\begin{array}{l}\text { Control values } \\
(n=12)\end{array}$ \\
\hline $\begin{array}{l}\text { ACA } \\
\text { aMCA } \\
\text { pMCA } \\
\text { PCA } \\
\text { pCO }(\mathrm{mmHg})\end{array}$ & $\begin{array}{l}49 \cdot 8,2 \cdot 3 \\
56 \cdot 8,3 \cdot 0 \\
53 \cdot 4,2 \cdot 8 \\
51 \cdot 4,2 \cdot 4\end{array}$ & $\begin{array}{l}49 \cdot 4,2 \cdot 3 \\
57 \cdot 8,3 \cdot 2 \\
53 \cdot 5,2 \cdot 6 \\
50 \cdot 3,2 \cdot 2\end{array}$ & $\begin{array}{l}56 \cdot 0,1 \cdot 3 \\
65 \cdot 9,1 \cdot 5 \\
58 \cdot 1,1 \cdot 3 \\
54 \cdot 4,1 \cdot 1 \\
40 \cdot 9,1 \cdot 1\end{array}$ & $\begin{array}{l}13 \cdot 4,0 \cdot 8 \\
15 \cdot 8,1 \cdot 1 \\
14 \cdot 2,1 \cdot 1 \\
14 \cdot 1,1 \cdot 3\end{array}$ & $\begin{array}{l}13 \cdot 6,1 \cdot 0 \\
16 \cdot 4,1 \cdot 3 \\
15 \cdot 6,1 \cdot 0 \\
13 \cdot 6,2 \cdot 4\end{array}$ & $\begin{array}{l}13 \cdot 5,1 \cdot 2 \\
15 \cdot 6,1 \cdot 6 \\
15 \cdot 0,1 \cdot 4 \\
15 \cdot 0,2 \cdot 1 \\
37 \cdot 8,1 \cdot 0\end{array}$ \\
\hline
\end{tabular}


well as the asymmetry of the response were within normal limits.

Before discussing the results of this study in detail we would like to stress that caution should be used when interpreting results based on a comparison between absolute $\mathrm{rCBF}$ values in patients with those in a control group. Findings may, at least partly be due to differences in $\mathrm{pCO}_{2}$ levels and to age. Several studies have demonstrated a decrease in CBF with increasing age, especially after the age of 60 years. ${ }^{90}$ In addition the individual response to acetazolamide may show considerable variations. The assessment of side-toside asymmetry in baseline $\mathrm{rCBF}$ values and the response to acetazolamide makes interpretation easier. Changes in baseline flow and in flow pattern after acetazolamide are then independent of random changes in flow and of $\mathrm{pCO}_{2}$ values.

The rCBF findings in group A suggest that these patients often have impaired cerebral haemodynamics even though they have not experienced symptoms of cerebral ischaemia. The clinical implications of these findings are at present unclear but may partly explain the increased risk for cerebral TIAs and stroke. ${ }^{45}$ In addition information regarding the cerebral haemodynamic significance of ICA lesions may indirectly be of help in predicting the risk of developing chronic ischaemic retinopathy. ${ }^{11} 12$

Retinal ischaemic symptoms in patients with ipsilateral carotid occlusive disease are most often due to emboli which have their origin in atheromatous ICA lesions. ${ }^{13}$ Four of the 11 patients in the present study with carotid occlusive disease ipsilateral to symptoms (Group A) had clinical evidence on ophthalmological examination suggesting emboli. One had central retinal artery occlusion and three patients had branch occlusion of this artery.

The occurrence of retinal ischaemic symptoms alone, without cerebral TIAs, is difficult to explain if the source of the emboli is an ipsilateral carotid lesion. It has been suggested, however, that an embolus in this situation may be of insufficient size or the arterial branches involved may be too small to cause clinical evidence of cerebral ischaemia. ${ }^{14}$

Reduced retinal perfusion pressure may have played a role in the development of symptoms in at least some of our patients with carotid occlusive disease (Group A). The rCBF examinations showed that cerebral vasoreactivity was reduced ipsilateral to the carotid lesion and it would therefore seem reasonable to assume that these lesions may also be of haemodynamic significance with regard to retinal blood flow. Although several studies have provided evidence which suggests that the eye and the brain have a similar autoregulation, ${ }^{15}$ it is possible that the retina is more sensitive to changes in perfusion pressure. ${ }^{16}$ Furthermore, the ICA was occluded in three of the 11 patients in group $\mathbf{A}$ who presented with amaurosis fugax. This may suggest that their visual symptoms were due to haemodynamic changes rather than emboli. However, the proximal and distal parts of the ICA occlusion may be a potential source of emboli in some patients in whom the emboli may reach the eye via the external carotid artery or from the stump of the occluded ICA. ${ }^{17}$

Baseline $\mathrm{rCBF}$ values were lower and the response to acetazolamide in the ACA territory was reduced in the cerebral hemisphere contralateral to the retinal symptoms in group A patients compared with controls. However, the patients with carotid occlusive disease were older (63, SEM $2 \cdot 7$ years) compared with controls (41, SEM 2.6 years) which may at least partly be responsible for the results. An alternative explanation is that contralateral cerebral vessels contributed to perfusion in the cerebral hemisphere ipsilateral to the carotid lesion. ${ }^{18}$ Conventional arteriography was carried out on all of these patients without the detection of atherosclerotic lesions in the intracranial arteries, except in two patients who had a slight stenosis of the carotid siphon contralateral to symptoms.

The patients in group B were examined by Doppler and IVDSA alone and we do not therefore have information regarding possible atherosclerotic lesions in the intracranial arteries. Four of these 17 patients had reduced baseline $\mathrm{CCBF}$ values in the MCA and/or ACA territories ipsilateral to symptoms, compared with the contralateral side. The response to acetazolamide was, however, symmetrical and within normal limits in these regions. Cerebral CT examination was normal in all patients. One possible explanation for the low-flow areas in these four patients is ischaemic damage with selective neuronal loss, which has been termed incomplete infarction. ${ }^{1920}$

Mean baseline rCBF values for the 17 patients who did not have evidence of carotid occlusive disease were reduced on both the symptomatic and contralateral sides compared to controls. The response to acetazolamide was within normal limits on both sides in all regions. Patients in this group were also older (50, SEM 3.7 years) than the controls (41, SEM 2.6 years) which again may at least partly explain the $\mathrm{rCBF}$ findings. Although these results merit extreme caution in their interpretation, they suggest the presence of unilateral or bilateral areas with reduced rCBF in at least some patients with normal precerebral carotid arteries who present with retinal ischaemic symptoms alone.

A few authors have previously described localised areas with reduced cerebral perfusion in patients presenting with amaurosis fugax alone, and with no history of cerebral TIAs. Rees et al ${ }^{21}$ found cerebral low flow areas ipsilateral to amaurosis fugax attacks in one patient who had normal conventional arteriographic findings. A further four cases were reported by Harrison and Marshall. ${ }^{22}$ In the latter study information regarding possible atherosclerotic changes in the 


\section{0}

precerebral carotid arteries was not provided. Neither of these two studies included cerebral CT examination. Vorstrup et al $^{23}$ described three patients with a normal cerebral CT examination and low flow areas in the MCA perfusion territory ipsilateral to their amaurosis fugax attacks. Two of these patients had angiographically demonstrated ipsilateral ICA stenosis and one severe stenosis of the innominate artery with subclavian steal.

There is some evidence suggesting that there may be an increased incidence of silent cerebral infarctions and cerebral atrophy, in patients who have experienced amaurosis fugax without cerebral symptoms. Grigg et al ${ }^{24}$ reported cerebral CT findings in 70 patients who presented with amaurosis fugax alone. Forty-three per cent of these patients had findings consistent with infarction, and $25 \%$ of localised or generalised cortical or central atrophy when the CT examinations were assessed independently. In 29 cerebral hemispheres without evidence of ipsilateral precerebral carotid occlusive disease assessed by Duplex scanning, they found that $17 \%$ had cerebral CT evidence of infarction and $14 \%$ localised or generalised cortical or central atrophy.

Confirmation of areas with reduced cerebral perfusion in patients with retinal ischaemic symptoms alone, who do not have evidence of carotid occlusive disease, may suggest the presence of an embolic source other than the carotid artery. This is especially true if the findings are present in both cerebral hemispheres. Six $(35 \%)$ of the 17 patients in the present study without precerebral carotid occlusive disease (Group B), had clinical evidence suggesting emboli on ophthalmological examination. One possibility is that these patients have a cardiac source for embolism. Necropsy studies had shown that patients with embolic stroke often have a potential cardiac source. ${ }^{25}$ However, in clinical studies it has proved to be difficult to diagnose cardiogenic emboli with certainty. ${ }^{26}$ Cardiological evaluation in the present study did not reveal abnormalities. Another possibility is that these patients may have a coagulation defect or haematological disease, which may provoke thrombosis or the formation of emboli. ${ }^{2728}$

In conclusion, the results of this study suggest that patients with retinal ischaemic symptoms alone due to carotid atherosclerosis often have a carotid lesion which is of haemodynamic significance with regard to cerebral perfusion. Furthermore, localised areas with reduced cerebral blood flow may also be present in at least some patients who do not have precerebral carotid occlusive disease.

\section{References}

1 Miller Fisher C. Transient monocular blindness associated with hemiplegia. Arch Ophthal 1952;47:167-203.

2 Marshall J, Meadows S. The natural history of amaurosis fugax. Brain 1968;91:419-34.

3 Adams HP, Putman SF, Corbett JJ, Sines BP, Thompson HS.
Kerty, Russell, Bakke, Nyberg-Hansen, Rootwelt

Amaurosis fugax: the results of arteriography in 59 patients. Stroke 1983;14:742-44.

4 Poole CJM, Ross Russell RW. Mortality and stroke after amaurosis fugax. J Neurol Neurosurg Psychiatry 1985;48:902-5.

5 Howard RS, Ross Russell RW. Prognosis of patients with retinal embolism. J Neurol Neurosurg Psychiatry 1987;50:1142-7.

6 Russell D, Lindegaard K-F, Nakstad P, Nyberg-Hansen R, C Øygarden KC. Detection of carotid occlusive disease by pulsed Doppler spectral analysis. J Neurol Neurosurg Psychiatry 1984; 47:1307-13.

7 Rootwelt K, Dybevold S, Nyberg-Hansen R, Russell D. Measurement of cerebral blood flow with ${ }^{133} \mathrm{Xe}$ inhalation and dynamic single photon emission computer tomography. Normal values. Scand J Clin Lab Invest 1986;46:(Suppl. 184):97-105.

8 Kendall M, Stuart A. The Advanced Theory of Statistics. Vol II. London: Charles Griffin and Co Ltd, 1960.

9 Shirahata N, Henriksen L, Vorstrup S, et al. Regional cerebral blood flow assessed by ${ }^{133} \mathrm{Xe}$ inhalation and emission tomo- 0 graphy: Normal values. J Comput Assist Tomogr 1985;9:861-6. के

10 Devous MD, Stokeley EM, Chehabi HH, Bonte FJ. Normal distribution of regional cerebral blood flow measured by $?$ dynamic single-photon emission tomography. J Cerebr Blood Flow Metabol 1986;6:95-104.

11 Kearns TP, Hollenhorst RW. Venous stasis retinopathy of occlusive disease of the carotid artery. Mayo Clin Proc 1963; 38:304-12.

12 Carter JE. Chronic ocular ischaemia and carotid vascular disease. Stroke 1985;16:721-8.

13 Mohr JP, Pessin MS. Extracranial carotid artery disease. In: $\vec{N}$ Barrett HJM, Mohr JP, Stein BM, Yatsu FM, eds. Stroke Pathophysiology, Diagnosis and Management. New York: Chub $\omega$ chill-Livingstone, 1986:293-336.

14 Pessin MS, Duncan GW, Mohr JP, Poskanzer DC. Clinical an angiographic features of carotid transient ischemic attacks. Engl J Med 1977:7:358-62.

15 Johnson PC. Review of previous studies and current theories autoregulation. Circ Res 1964. 15(suppl 1):2-8.

16 Ross Russell RW, Page GR. Critical perfusion of brain and retime Brain 1983;106:419-34.

17 Countee RW, Vijayanathan T, Chavis P. Recurrent reting ischemia beyond cervical carotid occlusions. $J$ Neurosurg 1981;55:532-42.

18 Robertson WM, Welch KMA, Tilley BC, Ewing JR. Cerebral blood flow asymmetry in the detection of extracranial cerebrovascular disease. Stroke 1988;19:813-9.

19 Lassen NA. Incomplete cerebral infarction-focal incomplete ischemic tissue necrosis not leading to emollison. Strok 1982;13:522-3

20 Marcoux FW, Morawetz RB, Crowell RM, DeGirolami U, Halsey JH. Differential regional vulnerability in transient foca cerebral ischemia. Stroke 1982;13:339-46.

21 Rees JE, Bull JWD, Ross Russell RW, Du Boulay GH, Marshall J, Symon L. Regional cerebral blood flow in transient ischaemic attacks. Lancet 1970;ii:1210-3.

22 Harrison MJG, Marshall J. Evidence of silent cerebral embolism in patients with amaurosis fugax. J Neurol Neurosurg Psychiatry 1977; 40:651-4.

23 Vorstrup S, Hemmingsen R, Henriksen L, Lindewald H, Engell HC, Lassen NA. Regional cerebral blood flow in patients with transient ischemic attacks studied by Xenon-133 inhalation and emission tomography. Stroke 1983;16:903-10.

24 Grigg MJ, Papadakis K, Nicolaides AN, et al. The significance of cerebral infarction and atrophy in patients with amaurosis fugax and transient ischemic attacks in relation to internal carotid artery stenosis. J Vasc Surg 1988;7:215-22.

25 Jørgensen L, Torvik A. Ischaemic cerebrovascular diseases in an autopsy series. J Neurol Sci 1966;3:410-32.

26 Cerebral Embolism Task Force. Cardiogenic brain embolism. Arch Neurol 1986;43:71-84.

27 Preston FE, Martin JF, Stewart RM, David-Jores GAB. Thrombocytosis, circulating platelet aggregates and neurological dysfunction. Br Med J 1979;2:1561-3.

28 Poole CJM, Ross Russell RW, Harrison P, Savidge GF. Amaurosis fugax under the age of 40 years. $J$ Neurol Neurosurg Psychiatry 1987;50:81-4.

\section{.}

